\title{
Gender differences in musical instrument choice
}

\section{Susan Hallam, Lynne Rogers, and Andrea Creech}

\section{Institute of Education, University of London}

Contact Susan Hallam, Institute of Education, University of London, 20 Bedford Way, London, WC1H OAL. Telephone 02076126371 E-mail s.hallameioe.ac.uk

This article is submitted exclusively to the International Journal of Music Education and, if accepted for publication, it is agreed that it will become the copyright of the International Society for Music Education. 


\begin{abstract}
Historically, there have been differences in the musical instruments played by boys and girls with girls preferring smaller, higher pitched instruments. This paper explores whether these gender preferences have continued at a time when there is greater gender equality in most aspects of life in the United Kingdom. Data were collected from the 150 Music Services in England as part of a larger survey. Some provided data regarding the sex of pupils playing each instrument directly. In other cases, the pupils' names and instruments were matched with data in the national Common Basic Data Set to establish gender. The findings showed distinctive patterns for different instruments. Girls predominated in harp, flute, voice, fife/piccolo, clarinet, oboe, and violin and boys in electric guitar, bass guitar, tuba, kit drums, tabla and trombone. The least gendered instruments were African drums, cornet, French horn, saxophone and tenor horn. The gendered pattern of learning was relatively consistent across education phases with a few exceptions. A model was developed which sets out the various influences which may explain the continuation of historical trends in instrument choice given the increased gender equity in UK society.
\end{abstract}


Key words: Age, Gender, Musical instrument preferences 


\section{Short biographies}

Dr Susan Hallam is Professor of Education at the Institute of Education, University of London and currently Head of the Institute's School of Lifelong Education and International Development. She pursued careers as both a professional musician and a music educator before becoming an academic in 1991. Her research interests include disaffection from school, ability grouping and homework and issues relating to learning in music, practising, performing, musical ability, musical understanding and the effects of music on behaviour and studying. She is the author of ten books including Instrumental Teaching: A Practical Guide to Better Teaching and Learning (1998), The Power of Music (2001) and Music Psychology in Education (2005) and over one hundred other scholarly contributions. She is past editor of Psychology of Music, Psychology of Education Review, and Learning Matters. She is past Chair of the Education Section of the British Psychological Society, treasurer of the British Educational Research Association, an auditor for the Quality Assurance Agency and an Academician of the Learned Societies for the Social Sciences.

Dr Andrea Creech has followed careers as a professional musician, music administrator and researcher. She has held principal positions in Canadian and British orchestras, and was cofounder and Director of Clare Music Makers, a community music school in Ireland. More recently Andrea has worked on research teams for several education projects and currently is Researcher in the School of Arts and Humanities, Institute of Education, London and facilitator for Doctoral School Research Methods training courses. Her special research interests are musical development across the lifespan and the impact of interpersonal relationships on learning and teaching outcomes. Andrea has presented her work at international conferences and published widely. 
Dr Lynne Rogers is Lecturer in Teacher Education 14-19 Psychology at The Institute of Education, University of London. She had extensive experience of work in schools as a music teacher and in a range of management positions prior to becoming an academic. She has undertaken extensive research in relation to behaviour in school; parenting programmes; disaffection from school including the role of alternative curricula; learning, studying and homework in adolescents; and issues relating to music education. Her publications include reports for the Department for Education and Skills and academic journal articles. She is currently secretary of the Education Section of the British Psychological Society. 


\section{Introduction}

Historically, all cultures have differentiated the roles of males and females. The nature and extent of this differentiation has varied between cultures and within them depending on other factors, for instance, social class, religious beliefs (Maccoby, 1988; Unger and Crawford, 1992). One aspect of this differentiation has been the gender-stereotyping of the musical activities which are perceived as appropriate for males and females and, in parallel with this, the gender-stereotyping of particular instruments. The latter may depend on a range of factors including the shape or size of the instrument, its pitch, quality of sound, or the need for particular characteristics in order to play it, for instance, physical endurance. While examples of these differences can be found in many cultures, most large-scale explorations of the gender-stereotyping of musical instruments have been carried out in the developed world in relation to Western instruments.

The cultural gender-stereotyping of instruments inevitably has an impact on the preferences of boys and girls for playing particular instruments leading to girls typically preferring to play smaller, higher pitched instruments. There are also other differences in the ways in which boys and girls engage with music. There is extensive evidence from around the world that boys are under represented in those learning to play an instrument (ABRSM, 1994; Acker, 1994; Gates, 1989; Green, 1993; 1997; Hanley, 1998, Koza, 1994; Mizener, 1993). Girls also tend to perform better in school music examinations (DES, 1991; Agak, 2002), despite there being no consistent gender differences in measured musical ability (Shuter-Dyson and Gabriel, 1981; Apfelstadt, 1984; Gordon, 1986), or teachers' ratings of musical ability (Hallam, 2004a). Girls also report more positive competence beliefs and values for instrumental music than boys (Eccles, Wigfield, Harold and Blumenfeld, 1993; Crowther and 
Durkin, 1982), although positive attitudes towards music increase with age for both genders (Crowther and Durkin, 1982). Boldizar (1991) found that children with higher 'feminine' scores on the Children's Gender Role Inventory gave higher rankings for music suggesting that music was regarded by males and females as a 'feminine' subject (Colley, Comber and Hargreaves, 1994), although boys demonstrate more interest in music when it is linked to technology and report more positive attitudes towards and confidence in using music technology than girls (Comber, Hargreaves and Colley, 1993).

Green (1997), in a qualitative study of secondary school students and teachers regarding their perceptions of girls and boys participation in and responses to musical activity, found that girls were perceived to be interested and successful in singing, playing classical music and in dealing with notation while boys were seen to have greater confidence in improvisation and composition. Green also reported that girls were perceived to be more persistent and more successful with instrumental study and seemed to have a broader listening repertoire and to be open to a wider range of musical styles than boys. Hargreaves, Comber and Colley (1995) came to similar conclusions. There is also evidence that the association of music technology with composition in the secondary school classroom has led to boy's greater involvement in this area of music and that the 'masculine' technological nature of popular music may have led to boys' higher levels of engagement with instrumental performance within this genre. (Green, 1997). These findings have been replicated in Canadian schools (Hanley, 1998).

Historically, instruments such as drums, trombone and trumpet have tended to be played more by boys, while flute, violin and clarinet have tended to be played by girls (Abeles and Porter, 1978). Recently, Sheldon and Price (2005) carried out an extensive survey of gender and instrumentation in wind and percussion ensembles from 25 countries including 8146 children. The data showed a gender-bias in instrument selections. There was a preponderance of 
females in the upper woodwinds with flute dominating followed by oboe, clarinet and bassoon. There was a prevalence of males in the remaining sections with tuba dominating, followed by euphonium, trombone, trumpet and percussion. More males played saxophones and horn but the proportions were less disparate. This trend was almost world wide with the exception of Asia, where female instrumentalists predominated. This supports findings from earlier research and that by Cramer, Million, and Perreault (2002), Fortney, Boyle and DeCarbo (1993) and Trollinger (1993).

These instrument gender-stereotypes seem to be shared by parents (Delzell and Leppla, 1992). For instance, from a selection of 8 instruments, clarinets, flutes and violins were preferred by parents for girls, while drums, trombones and trumpets were preferred for boys. The cello and the saxophone were seen as having no significant gender association (Abeles and Porter, 1978). Another study, which included more instruments, showed that parents preferred harp, piccolo, glockenspiel, cello, piano, French horn and oboe for girls to learn while guitar, cymbals, saxophone, double bass and tuba were preferred for boys (Griswold and Chroback, 1981).

Girls tend to select a wider variety of instruments which they would like to play along the feminine - masculine continuum than boys. Zervaoudakes and Tanur collecting data between 1959 and 1990 showed an increase in the proportion of females who played both feminine and masculine instruments. The effects were greatest at the primary school, with stereotypical choices remaining at secondary level (Zervoudakes and Tanur, 1994). There is some evidence that these stereotypical preferences can be changed. Presenting instruments to children aurally and visually without players can encourage boys to select more feminine instruments, although it has little effect on girls' choices which continue to be selected from a wide range (Abeles and Porter, 1978). Changing the gender-role model playing the instrument has also 
been shown to be effective with children aged 5-7. When a female was playing a 'masculine' instrument more girls opted for playing it (Bruce and Kemp, 1993). Where children choose to play an instrument which is considered gender-inappropriate they may experience bullying or loss of popularity in school (Howe and Sloboda, 1992). Children are aware of which instruments are gender typical and have clear ideas about which ones are likely to lead to bullying if they are played (O’Neill and Boulton, 1995; O’Neill, 1997).

In the UK, reflecting the changing role of women in society, girls are now more successful than boys in examinations in most subjects at most levels (DfES, 2005). This has been accompanied by an increase in girls 'laddish' behaviour (Jackson, 2006) and involvement in delinquency (Osler et al., 2002; Smith, 2004). Given these changes and the emphasis in the UK on equal opportunities, we might expect that gendered instrumental preferences would have changed over time. The aim of the study reported here was to establish the proportions of boys and girls playing different instruments within the English education system and whether these proportions remained consistent across each educational phase.

\section{Methodology}

The data analysed in this paper were derived from a larger survey study which was commissioned by the Department for Education and Skills to research the way that the 150 Local Authority Music Services in England were functioning. An extensive consultation process was undertaken with representatives of Music Services to ensure that the questionnaire which was developed was user friendly, easy to understand and addressed questions of relevance to them. The questionnaires were made available through commonly available word processing packages and offered over e-mail or, if required, in paper form. 
Where Music Services had access to information about pupil's biological sex they were asked to supply it in relation to the instrument being learned. Where this was not the case, Music Services were asked to supply pupil names, year group and instrument on a data-base. These data were then matched with that from the national Common Basic Data Set to provide information about pupil sex, special educational needs, ethnicity and free school meals. Where Music Services had devolved funding to schools and pupil lists were not available centrally, Local Authorities (LAs) were asked to provide a list of names of pupils learning and their instruments which could then be tracked through the Common Basic Data Set. Where LAs provided pupil data electronically, data were matched using either the Unique Pupil Number (UPN), the pupil's name, the school or key stage.

Even where UPNs were available for pupils the matching process was not perfect. Where the first point of matching was the pupil's name there were difficulties because of inaccurate spelling. Using more means of identification, school and year group only served to reduce the numbers matched as there were more variables where there was the possibility of inaccuracy. On average the matching process was $80 \%$ successful. This means that data based on the process are systematically an underestimate. However, missing data were randomly distributed between Music Services, so the proportions of children of each sex learning each instrument in each year group are fairly represented in this paper. Data were analysed to calculate the percentage of boys and girls learning each instrument in each education phase and overall.

\section{Findings}

Music Services offered a very wide range of musical instruments for pupils to learn. In addition to the instruments listed in Table 1 the 'other' category included a range of Indian, 
West Indian, South American, Eastern European and African instruments. In addition, there were examples of the provision of tuition of early music (viols, harpsichord, lute) alongside rock music instruments, DJ-ing, music technology and a variety of folk musics, and other less common instruments (fife, harmonium, harmonica, ocarina, tin whistle, mandolin, hand-bells, banjo). Relatively few Music Services provided tuition for pre-school children. The level of tuition increased through the primary years with the largest proportion of tuition taking place between the ages of 7 and 11 .

Table 1 provides the details of the total number of children playing each instrument in each key stage. Key Stage 1 (KS1) includes children aged 5-7, Key Stage 2 (KS2) children aged 7-11, Key Stage 3 (KS3) children aged 11-14 and Key Stage 4 (KS4) children aged 14-16. Pupils in the post 16 category are aged 16-19. Data were also collected for pupils learning pre-school and those aged 19 and over. The numbers learning pre-school were very small and have not been included separately in the table although they do contribute to the overall totals. Gender information was not available for pupils aged 19 and over so they have not been included.

The overall gender differences in playing instruments and an overview of the relative numbers learning each instrument are provided in Table 1 . The instrument most commonly played was the violin (19\%) probably because it is relatively cheap to buy and is available in a range of sizes for young children. The next highest group consisted of pupils playing guitar, including acoustic, electric, bass and undifferentiated (16.3\%), followed by flute $(10 \%)$ and clarinet (9\%). Seven percent of children played keyboard, $4.3 \%$ kit drum, $4.5 \%$ the piano, $4.6 \%$ the trumpet, and $4 \%$ had voice training. More children learned to play African drums and steel pans than the bassoon, baritone, euphonium, French horn, saxophone, oboe, tuba and recorder. 
Overall, $60 \%$ of those learning were girls. This proportion changed from $51 \%$ in pre-school to $57 \%$ in $\mathrm{KS} 1$ and then remained stable at $60 \%$ for the remainder of compulsory schooling. The most gendered instruments were the harp (90\% girls), flute (89\% girls), electric guitar ( $81 \%$ boys), bass guitar ( $81 \%$ boys), voice ( $80 \%$ girls), fife/piccolo (79\% girls), oboe (78\% girls), tuba ( $77 \%$ boys), kit drum ( $75 \%$ boys), tabla ( $74 \%$ boys), clarinet ( $73 \%$ girls), and trombone ( $71 \%$ boys). The least gendered instruments were African drums, cornet, French horn, saxophone and tenor horn. The gendered pattern of playing was relatively consistent across all key stages with some exceptions.

The small number of pupils learning to play any instrument in KS1 and post 16 meant that these were not reliable indicators of gender differences. If we ignore both $\mathrm{KS} 1$ and post 16 data where the sample sizes were much smaller, there is a consistently higher proportion of girls playing the bassoon and the piano and boys playing acoustic guitar, electric guitar, trombone, and trumpet at a ratio of about 2:1 in all key stages. In some instruments where girls predominate this domination increases at the point of change to the secondary phase, for instance, in relation to playing the cello, clarinet, viola, and violin. The same pattern occurs in relation to the flute and oboe, but these were already more heavily gendered at primary school. The most dramatic change occurred in relation to voice tuition, where there was a huge increase in the proportion of girls taking tuition at KS3 largely because of the large decrease in boys receiving tuition. This may have been related to boys' voices breaking at around this age, although there was no subsequent increase in the later years of schooling. The proportions of boys and girls playing the recorder at KS2 were relatively similar but became more differentiated through $\mathrm{KS} 3$ and $\mathrm{KS} 4$, as did the playing of steel pans and tenor horn. 


\section{Table 1 about here}

There was a gradual increase in the percentage of boys learning African drums across all phases, bass guitar became more dominated by boys at secondary school as did guitar (undifferentiated). Double bass became more male dominated in KS4 after fairly even proportions played double bass in $\mathrm{KS} 2$ and $\mathrm{KS} 3$. The percentage of boys playing percussion increased at KS3 and then declined at KS4. Girls predominated in playing keyboards at KS2 but the proportion of boys increased through to KS4. In contrast, kit drumming was dominated by boys overall, but with a gradual increase in the proportion of girls at KS4.

For some instruments there were relatively few gender differences throughout the school years, for instance, cornet, French horn, saxophone, and the 'other' category. In some cases, while the proportion of boys was greater at all key stages, there was considerable variation in proportions of girls and boys between key stages, for instance the euphonium, music technology and baritone.

\section{Discussion}

At a time when gender equality is accepted as appropriate and desirable in most Western cultures and when girls are out performing boys in most subjects and phases of education in the UK, why do there continue to be such marked gender preferences for some musical instruments and so few for others. Why are there differences in the stability of those trends across educational phase? There are many possible contributory factors. Figure 1 sets out some of the possibilities categorizing them under three headings, social, individual and instrument factors. 


\section{Figure 1 about here}

Social factors which may be important include role models and stereo-typical expectations of which instruments are appropriate for each gender. Cultural factors, including those relating to religion may be important here. Parental influence may be important at primary school while peers may exert increasing influence as pupils approach adolescence. There is some evidence that siblings may also be influential, younger children sometimes deliberately choosing a different instrument to an older successful sibling to establish their own individual musical identity (Davidson and Borthwick, 2001).

At the level of the individual, the age of beginning to learn may determine initial choice, other factors influencing whether there is a change in instrument later on, continuation with the same instrument or cessation of all tuition. Depending on age children will have preferences for different types of sound, and musical genres. The way that physical interaction with the instrument occurs may be important. Boys may prefer instruments that are struck or require high levels of physical exertion. The technical difficulty of the instrument and level of persistence required to play it may also play a part as evidence indicates that boys tend to do less practice than girls (Hallam, 2004b). The increasing proportion of girls learning to play kit drums and electric guitar in the later phases of education suggests that the instrument choice is linked to the development of identity, Closely related to this is the extent to which value is attached to conforming to gender stereotypes. This may be an inhibitory factor for boys who may come under great pressure from peers if they engage in any activity which is seen as 'feminine'.

The nature of the instrument itself is also influential. Pitch, tone quality and appearance may all contribute to initial decisions about which instrument to play. There is much anecdotal 
evidence of individuals responding to the sound of a particular instrument. However, for some children, it may simply be an issue of access, which instruments are available in the particular school that they attend, their cost, and in the case of the large instruments whether transport is available. The way that the instrument is presented to the students may be influential, for instance, whether its performance is modeled by a male or female player. The extent to which pupils are aware of the gendered nature of a particular instrument, in conjunction with the way it is introduced within the education system may also be important, particularly in relation to those instruments from another culture, for instance, African drums. The physical requirements of some instruments may preclude some pupils learning to play them. Another consideration may be whether the repertoire for the instrument lends itself to solo or group music making.

The power of each of these factors to influence which instrument is played will vary. Where cost of the instrument and transport are not an issue the individual will have greater choice, although family influences may remain strong. Where opportunities are limited, children may have no choice of instrument simply being allocated what is available. Given the data from the survey it appears that even where there is apparently free choice, stereotypical views of masculinity and femininity still play an important part in determining choice. There is clearly a need for research which systematically explores the interactions between the various factors in the model outlined above in different cultures and contexts. Another fruitful area for exploration would be the circumstances under which boys and girls choose to play instruments which are gendered differently to their biological sex.

What are the implications of this for teachers? They need to be aware of the strongly gendered nature of instrument choice and make it clear to prospective pupils that it is entirely appropriate for them to play any instrument whether it is perceived as feminine or masculine 
in character. They also need to ensure that children playing instruments which are gendered differently to their biological sex, for instance, boys playing flutes, are not bullied as a result of their choices. If they wish to promote more cross gender instrumental playing they need to provide cross gendered role models particularly at demonstration sessions. A more radical option may be to have single gendered ensembles where there is a clear need for boys and girls to play the whole range of instruments to support the ensemble. Once such ensembles are established there will be plentiful role models for future pupils.

\section{References}

Abeles, H.F \& Porter, S.Y. (1978). The gender-stereotyping of musical instruments, Journal of Research in Music Education, 26(2), 65-75.

Acker, S. (1994). Gendered education. Toronto: OISE Press

Agak, H. (2002). Gender difference and academic achievement in music among Form Four students in Kenya 1991-1994, Bulletin of the Council for Research in Music Education, (153) 94-101.

Apfelstadt, H. (1984) Effects of melodic perception, instruction on pitch discrimination and vocal accuracy of kindergarten children, Journal of Research in Music Education, 32(1), 1524.

Associated Board of the Royal Schools of Music (1994). Making music: The Associated Board Review of the teaching, learning and playing of musical instruments in the United Kingdom. London: ABRSM. 
Boldizar, J.P. (1991). Assessing gender-typing and androgyny in children: The children's gender-role inventory, Development Psychology, 27, 505-15.

Bruce, R. and Kemp, A (1993). Gender stereotyping in children's preferences for musical instruments, British Journal of Music Education, 10, 213-17.

Colley, A. Comber, C., \& Hargreaves, D.J. (1994). Gender effects in school subject preferences: A research note, Educational Studies, 20, 13-18.

Comber, C., Hargreaves, D.J. \& Colley, A. (1993). Girls, boys, and technology in music education, British Journal of Music Education, 10, 123-34.

Cramer, K.M., Million, E., \& Perreault, L.A. (2002). Perception of musicians: Gender stereotypes and social role theory, Psychology of Music, 30(2), 164-174.

Crowther, R., \& Durkin, K. (1982). Gender and age related differences in the musical behaviour, interests and attitudes towards music of 232 secondary school students, Educational Studies, 8, 131-9.

Davidson, J., and Borthwick, S.J. (2002). Family dynamics and family scripts: A case study of musical development, Psychology of Music, 30, 121-136.

Delzell, J.K. \& Leppla, D. A. (1992). Gender association of musical instruments and preferences of fourth-grade students for selected instruments, Journal of Research in Music Education, 40, 93-103. 
Department for Education and Skills (1991). Music for Ages 5 to 14: Proposals of the Secretary of State for Education and Science and Secretary of State for Wales. London: HMSO

Department for Education and Skills (2005) Gender and Achievement. http://www.standards.dfes.gov.uk/genderandachievement/understanding/analysis/ accessed 28/04/07.

Eccles, J., Wigfield, A., Harold, R.D. \& Blumenfeld, P. (1993). Age and gender differences in children's self- and task perceptions during elementary school, Child Development, 64, 83047.

Fortney, P.M., Boyle, J.D., \& DeCarbo, N.J. (1993). A study of middle school band students' instrumental choices, Journal of Research in Music Education, 41, 28-39.

Gates, J.T. (1989). A historical comparison of public singing by American men and women, Journal of Research in Music Education, 37(1), 32-47.

Gordon, E. (1986) Primary measures in music audiation (revised). Chicago, IL: GIA

Green, L. (1993). Music, gender and education: A report of some exploratory research, British Journal of Music Education, 10, 219-253.

Green, L. (1997). Music, gender and education. NY: Cambridge University Press 
Griswold, P.A. \& Chroback, D.A. (1981). Gender role associations of music instruments and occupations by gender and major, Journal of Research in Music Education, 29(1), 57-62.

Hallam, S. (2004a). Sex differences in the factors which predict musical attainment in school aged students, Bulletin of the Council for Research in Music Education, Summer 2004, 161/16, 107-117.

Hallam, S. (2004b). How important is practising as a predictor of learning outcomes in instrumental music? In S.D. Lipscomb, R. Ashley, R.O. Gjerdingen \& P. Webster. Proceedings of the $8^{\text {th }}$ International Conference on Music Perception and Cognition, August 3-7 $7^{\text {th }}$ 2004. (pp 165-168) Evanston, USA: Northwestern University.

Hanley, B. (1998). Gender in secondary music education in British Columbia, British Journal of Music Education, 15(1), 51-6.

Hargreaves, D.J., Comber, C., \& Colley, A. (1995). Effects of age, gender and training on musical preferences of British secondary school students, Journal of Research in Music Education, 43(3), 242-250.

Howe, M.J.A. and Sloboda, J. (1992). Problems experienced by talented young musicians as a result of the failure of other children to value musical accomplishments, Gifted Education, 8, 16-18.

Jackson, C. (2006). Lads and Ladettes in School. Open University Press 
Koza, J.E. (1994). Big boys don’t cry (or sing): Gender, misogyny, and homophobia in college choral methods texts, Quarterly Journal of Music Teaching and Learning, 4,5(4,1) 48-64.

Maccoby, E.E. (1988) Gender as a social category, Developmental Psychology, 24, 755-65.

Mizener, C.P. (1993). Attitudes of children towards singing and choir participation and assessed singing skill, Journal of Research in Music Education, 41(3), 233-245.

O’Neill S.A. (1997). Gender and Music. In D.J. Hargreaves \& A.C. North (Eds.), The social psychology of music (pp. 46-63). Oxford: Oxford University Press

O’Neill, S.A. and Boulton, M.J. (1995). Is there a gender bias towards musical instruments: A function of gender? Psychology of Music, 24, 171-83.

Osler, A., Street, C., Lall, M., and Vincent, K. (2002). Not a problem? Girls and School Exclusion. London: National Children's Bureau.

Sheldon, D.A., \& Price, H.E. (2005). Gender and Instrumentation distribution in an international cross-section of wind and percussion ensembles, Bulletin of the Council for Research in Music Education, 163, 43-51.

Shuter-Dyson, R. \& Gabriel, C. (1981). The psychology of Musical ability (2nd edition) London: Methuen. 
Smith, M. (2004). Edinburgh Study of Youth Transitions and Crime. Edinburgh: University of Edinburgh.

Trollinger, L.M. (1993). Gender/Gender research in music education: A review, The Quarterly Journal of Music Teacher and Learning, 4, 22-39.

Unger, R. \& Crawford, M. (1992). Women and gender: A feminist psychology. New York: McGraw-Hill.

Zervoudakes, J. \& Tanur, J. (1994). Gender and musical instruments: Winds of change, Journal of Research in Music Education, 42, 58-67. 
Table 1: Total number of pupils learning each instrument at each key stage differentiated by gender

\begin{tabular}{|c|c|c|c|c|c|c|c|c|c|c|c|c|}
\hline \multirow[b]{2}{*}{ Instrument and \% } & \multicolumn{2}{|c|}{ Key Stage 1} & \multicolumn{2}{|c|}{ Key Stage 2} & \multicolumn{2}{|c|}{ Key Stage 3} & \multicolumn{2}{|c|}{ Key Stage 4} & \multicolumn{2}{|c|}{ Post 16 } & \multicolumn{2}{|l|}{ Total } \\
\hline & Girls & Boys & Girls & Boys & Girls & Boys & Girls & Boys & Girls & Boys & \begin{tabular}{|l|} 
Girls \\
\end{tabular} & Boys \\
\hline \multirow{2}{*}{$\begin{array}{l}\text { African drums } \\
\text { (undifferentiated) } \\
.8 \%\end{array}$} & $50 \%$ & $50 \%$ & $51 \%$ & $49 \%$ & $47 \%$ & $53 \%$ & $40 \%$ & $60 \%$ & & $100 \%$ & $50 \%$ & $50 \%$ \\
\hline & 125 & 126 & 1270 & 1221 & 249 & 280 & 36 & 54 & & 2 & 1680 & 1683 \\
\hline \multirow[t]{2}{*}{ Bassoon .3\% } & $86 \%$ & $14 \%$ & $56 \%$ & $44 \%$ & $64 \%$ & $36 \%$ & $61 \%$ & $39 \%$ & $67 \%$ & $33 \%$ & $62 \%$ & $38 \%$ \\
\hline & 6 & 1 & 171 & 133 & 294 & 162 & 133 & 86 & 72 & 35 & 676 & 417 \\
\hline \multirow[t]{2}{*}{ Baritone $.4 \%$} & $50 \%$ & $50 \%$ & $41 \%$ & $59 \%$ & $36 \%$ & $64 \%$ & $44 \%$ & $56 \%$ & $33 \%$ & $66 \%$ & $41 \%$ & $59 \%$ \\
\hline & 4 & 4 & 401 & 580 & 117 & 211 & 44 & 57 & 8 & 16 & 574 & 868 \\
\hline \multirow{2}{*}{ Cello 3\% } & $61 \%$ & $39 \%$ & $64 \%$ & $46 \%$ & $70 \%$ & $30 \%$ & $70 \%$ & $30 \%$ & $70 \%$ & $30 \%$ & $66 \%$ & $34 \%$ \\
\hline & 211 & 136 & 5206 & 2901 & 1922 & 829 & 721 & 313 & 290 & 122 & 8351 & 4301 \\
\hline \multirow[t]{2}{*}{ Clarinet 9\% } & $58 \%$ & $42 \%$ & $70 \%$ & $30 \%$ & $78 \%$ & $22 \%$ & $78 \%$ & $22 \%$ & $76 \%$ & $24 \%$ & $73 \%$ & $27 \%$ \\
\hline & 118 & 86 & 14047 & 6049 & 8816 & 2482 & 2856 & 797 & 856 & 265 & 26696 & 9680 \\
\hline \multirow[t]{2}{*}{ Cornet $2 \%$} & $48 \%$ & $52 \%$ & $47 \%$ & $53 \%$ & $52 \%$ & $48 \%$ & $50 \%$ & $50 \%$ & $55 \%$ & $45 \%$ & $48 \%$ & $52 \%$ \\
\hline & 60 & 65 & 2988 & 3372 & 1186 & 1103 & 286 & 286 & 75 & 61 & 4597 & 4888 \\
\hline \multirow[t]{2}{*}{ Double bass .4\% } & $60 \%$ & $40 \%$ & $47 \%$ & $53 \%$ & $50 \%$ & $50 \%$ & $42 \%$ & $58 \%$ & $46 \%$ & $54 \%$ & $47 \%$ & $53 \%$ \\
\hline & 3 & 2 & 312 & 346 & 223 & 226 & 105 & 145 & 54 & 63 & 697 & 782 \\
\hline \multirow[t]{2}{*}{ Euphonium .5\% } & $33 \%$ & $66 \%$ & $31 \%$ & $69 \%$ & $43 \%$ & $57 \%$ & $27 \%$ & $73 \%$ & $40 \%$ & $60 \%$ & $33 \%$ & $67 \%$ \\
\hline & 2 & 4 & 313 & 690 & 192 & 323 & 59 & 160 & 30 & 45 & 596 & 1222 \\
\hline \multirow[t]{2}{*}{ Flute 10\% } & $89 \%$ & $11 \%$ & $87 \%$ & $13 \%$ & $91 \%$ & $9 \%$ & $92 \%$ & $8 \%$ & $92 \%$ & $8 \%$ & $89 \%$ & $11 \%$ \\
\hline & 319 & 40 & 19147 & 2920 & 11301 & 1057 & 3739 & 334 & 1313 & 119 & 35823 & 4472 \\
\hline \multirow[t]{2}{*}{ French horn $.4 \%$} & $50 \%$ & $50 \%$ & $50 \%$ & $50 \%$ & $46 \%$ & $54 \%$ & $53 \%$ & $47 \%$ & $50 \%$ & $50 \%$ & $49 \%$ & $51 \%$ \\
\hline & 3 & 3 & 460 & 452 & 248 & 286 & 101 & 91 & 56 & 56 & 868 & 888 \\
\hline \multirow[t]{2}{*}{ Gamelan .2\% } & $55 \%$ & $45 \%$ & $57 \%$ & $43 \%$ & $82 \%$ & $18 \%$ & $74 \%$ & $26 \%$ & $50 \%$ & $50 \%$ & $58 \%$ & $42 \%$ \\
\hline & 31 & 25 & 368 & 282 & 37 & 8 & 23 & 8 & 8 & 8 & 467 & 331 \\
\hline \multirow{2}{*}{$\begin{array}{l}\text { Guitar (acoustic) } \\
8 \%\end{array}$} & $34 \%$ & $66 \%$ & $37 \%$ & $63 \%$ & $35 \%$ & $65 \%$ & $36 \%$ & $64 \%$ & $37 \%$ & $63 \%$ & $36 \%$ & $64 \%$ \\
\hline & 421 & 814 & 7790 & 13245 & 2885 & 5290 & 1038 & 1817 & 172 & 296 & 12315 & 21483 \\
\hline \multirow{2}{*}{$\begin{array}{l}\text { Guitar (electric) } \\
.9 \%\end{array}$} & & $100 \%$ & $14 \%$ & $86 \%$ & $18 \%$ & $82 \%$ & $20 \%$ & $80 \%$ & $22 \%$ & $78 \%$ & $19 \%$ & $81 \%$ \\
\hline & & 3 & 27 & 162 & 405 & 1803 & 246 & 993 & 47 & 165 & 725 & 3126 \\
\hline \multirow[t]{2}{*}{ Guitar (bass) $.4 \%$} & & $100 \%$ & $36 \%$ & $64 \%$ & $18 \%$ & $82 \%$ & $19 \%$ & $81 \%$ & $20 \%$ & $80 \%$ & $19 \%$ & $81 \%$ \\
\hline & & 6 & 29 & 52 & 143 & 642 & 122 & 531 & 19 & 75 & 313 & 1306 \\
\hline Guita & $34 \%$ & $66 \%$ & $40 \%$ & $60 \%$ & $37 \%$ & $63 \%$ & $31 \%$ & $69 \%$ & $24 \%$ & $76 \%$ & $38 \%$ & $62 \%$ \\
\hline & 178 & 342 & 5950 & 8782 & 2669 & 4581 & 851 & 1876 & 90 & 281 & 9745 & 15869 \\
\hline Harp .02\% & & & $85 \%$ & $5 \%$ & $89 \%$ & $11 \%$ & $91 \%$ & $9 \%$ & $100 \%$ & & $90 \%$ & $10 \%$ \\
\hline & & & 11 & 2 & 24 & 3 & 10 & 1 & 7 & & 52 & 6 \\
\hline Keyboard 7\% & $58 \%$ & $42 \%$ & $62 \%$ & $38 \%$ & $60 \%$ & $40 \%$ & $55 \%$ & $45 \%$ & $50 \%$ & $50 \%$ & $62 \%$ & $38 \%$ \\
\hline & 694 & 499 & 10523 & 6563 & 4508 & 3007 & 1387 & 1133 & 90 & 90 & 18352 & 11306 \\
\hline Kit drums $4.3 \%$ & $17 \%$ & $83 \%$ & $22 \%$ & $78 \%$ & $24 \%$ & $76 \%$ & $28 \%$ & $72 \%$ & $39 \%$ & $61 \%$ & $25 \%$ & $75 \%$ \\
\hline & 20 & 96 & 818 & 2963 & 1982 & 6325 & 984 & 2579 & 178 & 282 & 3982 & 12247 \\
\hline Music Technology & & $100 \%$ & $46 \%$ & $54 \%$ & $40 \%$ & $60 \%$ & $44 \%$ & $56 \%$ & $25 \%$ & $75 \%$ & $43 \%$ & $57 \%$ \\
\hline $.4 \%$ & & 1 & 278 & 326 & 138 & 204 & 173 & 221 & 26 & 77 & 615 & 829 \\
\hline Oboe $.6 \%$ & $40 \%$ & $60 \%$ & $67 \%$ & $33 \%$ & $78 \%$ & $22 \%$ & $75 \%$ & $25 \%$ & $84 \%$ & $16 \%$ & $78 \%$ & $22 \%$ \\
\hline & 2 & 3 & 546 & 273 & 761 & 210 & 295 & 82 & 183 & 36 & 1787 & 605 \\
\hline Percussion & $43 \%$ & $57 \%$ & $33 \%$ & $67 \%$ & $25 \%$ & $75 \%$ & $31 \%$ & $69 \%$ & $34 \%$ & $66 \%$ & $30 \%$ & $70 \%$ \\
\hline (orch & 64 & 84 & 1178 & 2428 & 932 & 2767 & 534 & 1162 & 117 & 224 & 2827 & 6666 \\
\hline
\end{tabular}


Table 1 (continued)

\begin{tabular}{|c|c|c|c|c|c|c|c|c|c|c|c|c|}
\hline & \multicolumn{2}{|c|}{ Key Stage 1} & \multicolumn{2}{|c|}{ Key Stage 2} & \multicolumn{2}{|c|}{ Key Stage 3} & \multicolumn{2}{|c|}{ Key Stage 4} & \multicolumn{2}{|c|}{ Post 16} & \multicolumn{2}{|l|}{ Total } \\
\hline Instrument and \% & Girls & Boys & Girls & Boys & Girls & Boys & Girls & Boys & Girls & Boys & Girls & Boys \\
\hline \multirow[t]{2}{*}{ Piano $4.5 \%$} & $60 \%$ & $40 \%$ & $67 \%$ & $33 \%$ & $69 \%$ & $31 \%$ & $65 \%$ & $35 \%$ & $62 \%$ & $38 \%$ & $66 \%$ & $34 \%$ \\
\hline & 705 & 472 & 5593 & 2777 & 3542 & 1593 & 1751 & 963 & 376 & 227 & 11982 & 6044 \\
\hline \multirow[t]{2}{*}{ Recorder .3\% } & $50 \%$ & $50 \%$ & $51 \%$ & $49 \%$ & $59 \%$ & $41 \%$ & $66 \%$ & $34 \%$ & $61 \%$ & $39 \%$ & $55 \%$ & $45 \%$ \\
\hline & 68 & 67 & 104 & 101 & 62 & 43 & 29 & 15 & 19 & 12 & 292 & 243 \\
\hline \multirow[t]{2}{*}{ Saxophone $.4 \%$} & $38 \%$ & $62 \%$ & $50 \%$ & $50 \%$ & $48 \%$ & $52 \%$ & $50 \%$ & $50 \%$ & $51 \%$ & $49 \%$ & $50 \%$ & $50 \%$ \\
\hline & 9 & 15 & 101 & 100 & 112 & 120 & 110 & 109 & 79 & 75 & 414 & 421 \\
\hline \multirow[t]{2}{*}{ Sitar .03\% } & & & $53 \%$ & $47 \%$ & $87 \%$ & $13 \%$ & $75 \%$ & $25 \%$ & & & $63 \%$ & $37 \%$ \\
\hline & & & 42 & 38 & 27 & 4 & 3 & 1 & & & 72 & 43 \\
\hline \multirow[t]{2}{*}{ Steel Pans 1.6\% } & $61 \%$ & $39 \%$ & $55 \%$ & $45 \%$ & $61 \%$ & $39 \%$ & $66 \%$ & $34 \%$ & $73 \%$ & $27 \%$ & $58 \%$ & $42 \%$ \\
\hline & 30 & 19 & 2219 & 1794 & 1033 & 671 & 365 & 186 & 37 & 14 & 3687 & 2687 \\
\hline \multirow[t]{2}{*}{ Tabla .1\% } & $21 \%$ & $79 \%$ & $26 \%$ & $74 \%$ & $25 \%$ & $75 \%$ & $29 \%$ & $71 \%$ & $50 \%$ & $50 \%$ & $26 \%$ & $74 \%$ \\
\hline & 6 & 22 & 72 & 208 & 29 & 87 & 5 & 12 & 5 & 5 & 118 & 334 \\
\hline \multirow[t]{2}{*}{ Tenor Horn .8\% } & $40 \%$ & $60 \%$ & $51 \%$ & $49 \%$ & $54 \%$ & $46 \%$ & $60 \%$ & $40 \%$ & $58 \%$ & $42 \%$ & $52 \%$ & $48 \%$ \\
\hline & 17 & 26 & 1135 & 1097 & 397 & 342 & 126 & 85 & 48 & 35 & 1723 & 1585 \\
\hline \multirow[t]{2}{*}{ Trombone $1.5 \%$} & $17 \%$ & $83 \%$ & $31 \%$ & $69 \%$ & $28 \%$ & $72 \%$ & $30 \%$ & $70 \%$ & $19 \%$ & $81 \%$ & $29 \%$ & $71 \%$ \\
\hline & 4 & 20 & 1043 & 2339 & 468 & 1217 & 172 & 402 & 47 & 196 & 1734 & 4175 \\
\hline \multirow[t]{2}{*}{ Trumpet $4.6 \%$} & $10 \%$ & $90 \%$ & $38 \%$ & $62 \%$ & $38 \%$ & $62 \%$ & $36 \%$ & $64 \%$ & $34 \%$ & $66 \%$ & $37 \%$ & $63 \%$ \\
\hline & 39 & 357 & 4090 & 6702 & 1743 & 2904 & 487 & 876 & 155 & 301 & 6615 & 11143 \\
\hline \multirow[t]{2}{*}{ Tuba .2\% } & & $100 \%$ & $21 \%$ & $79 \%$ & $23 \%$ & $77 \%$ & $24 \%$ & $76 \%$ & $28 \%$ & $72 \%$ & $23 \%$ & $77 \%$ \\
\hline & & 2 & 48 & 185 & 64 & 211 & 36 & 112 & 20 & 52 & 168 & 562 \\
\hline \multirow[t]{2}{*}{ Voice $4 \%$} & $51 \%$ & $49 \%$ & $61 \%$ & $39 \%$ & $90 \%$ & $10 \%$ & $88 \%$ & $12 \%$ & $83 \%$ & $17 \%$ & $80 \%$ & $20 \%$ \\
\hline & 373 & 357 & 2303 & 1466 & 5346 & 626 & 4501 & 606 & 884 & 178 & 13479 & 3312 \\
\hline \multirow[t]{2}{*}{ Viola $.9 \%$} & $64 \%$ & $36 \%$ & $66 \%$ & $34 \%$ & $74 \%$ & $26 \%$ & $74 \%$ & $26 \%$ & $76 \%$ & $24 \%$ & $69 \%$ & $31 \%$ \\
\hline & 30 & 17 & 1502 & 767 & 611 & 215 & 231 & 82 & 114 & 36 & 2489 & 1117 \\
\hline \multirow[t]{2}{*}{ Violin 19\% } & $66 \%$ & $34 \%$ & $73 \%$ & $27 \%$ & $79 \%$ & $21 \%$ & $76 \%$ & $24 \%$ & $75 \%$ & $25 \%$ & $74 \%$ & $26 \%$ \\
\hline & 3167 & 1620 & 38885 & 14219 & 10233 & 2678 & 2797 & 908 & 874 & 288 & 56000 & 19763 \\
\hline \multirow{2}{*}{$\begin{array}{l}\text { Other fife/ piccolo } \\
.1 \%\end{array}$} & $80 \%$ & $20 \%$ & $78 \%$ & $22 \%$ & $85 \%$ & $15 \%$ & $90 \%$ & $10 \%$ & $100 \%$ & & $79 \%$ & $21 \%$ \\
\hline & 16 & 4 & 374 & 104 & 11 & 2 & 9 & 1 & 2 & & 412 & 111 \\
\hline \multirow{2}{*}{$\begin{array}{l}\text { Other flugel horn } \\
.02 \%\end{array}$} & $100 \%$ & & $63 \%$ & $27 \%$ & $43 \%$ & $57 \%$ & $50 \%$ & $50 \%$ & $50 \%$ & $50 \%$ & $61 \%$ & $39 \%$ \\
\hline & 13 & & 25 & 15 & 10 & 13 & 4 & 4 & 2 & 2 & 54 & 34 \\
\hline \multirow{2}{*}{$\begin{array}{l}\text { Other unspecified } \\
1.5 \%\end{array}$} & $54 \%$ & $46 \%$ & $56 \%$ & $44 \%$ & $52 \%$ & $48 \%$ & $49 \%$ & $51 \%$ & $59 \%$ & $41 \%$ & $54 \%$ & $46 \%$ \\
\hline & 554 & 474 & 1662 & 1324 & 504 & 460 & 210 & 218 & 68 & 47 & 3038 & 2558 \\
\hline
\end{tabular}

* Data are an underestimation as up to $20 \%$ of pupils learning to play an instrument were unable to be matched with the Common Basic Data Set 


\section{Figure 1: Factors affecting instrument choice}

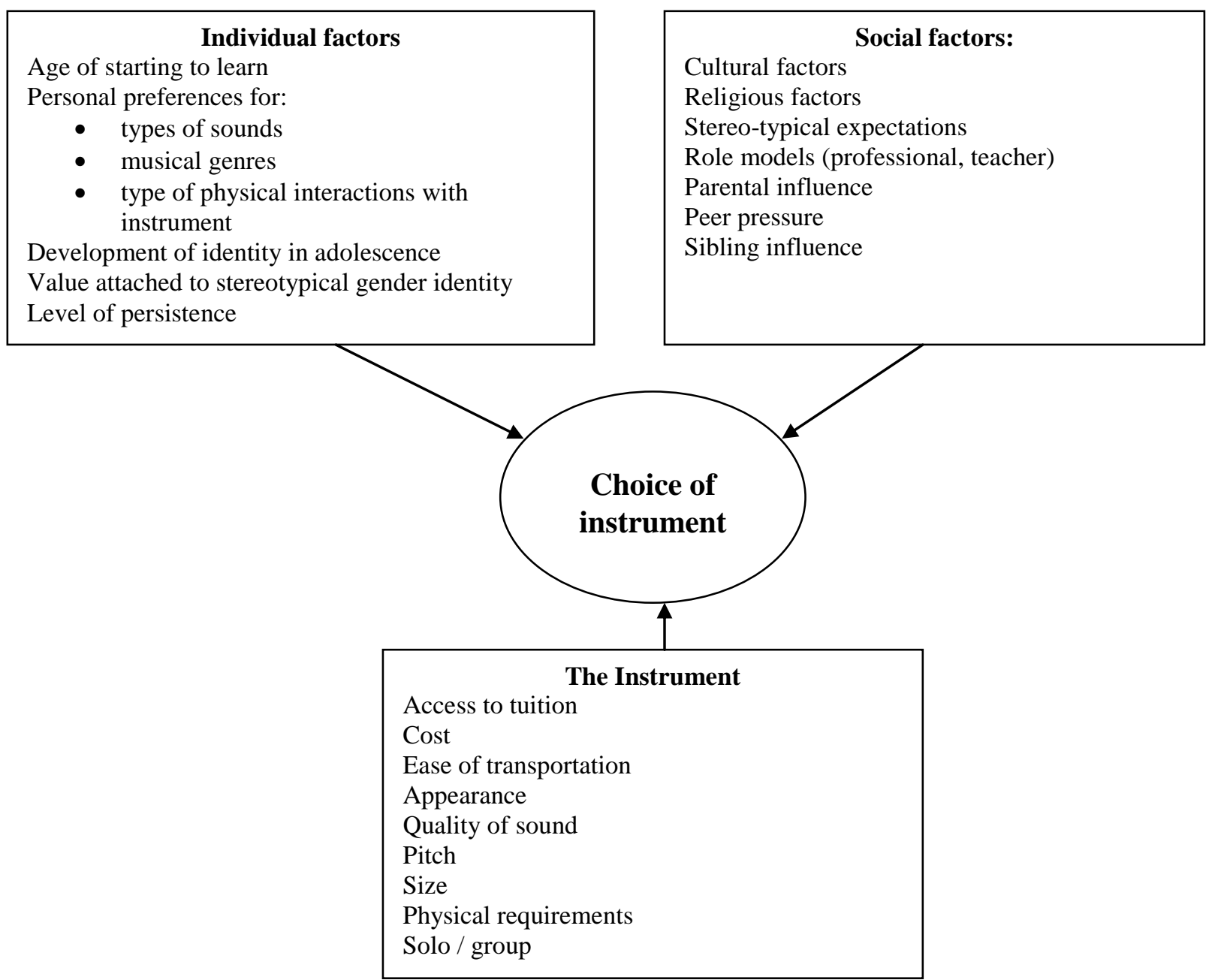

